Dept. of Pathology, Animal Health Research Institute, Alexandria Regional Laboratory.

\title{
PATHOLOGICAL STUDIES ON THE LIVER AFFECTIONS OF COWS AND CALVES IN SLAUGHTER HOUSES IN ALEXANDRIA GOVERNORATE
}

(With 3 Figures)

\author{
By \\ SANAA ABDO EL-SHAMY \\ and MARIEM SHOHDY BEKHIT
}

(Received at 14/3/2011)

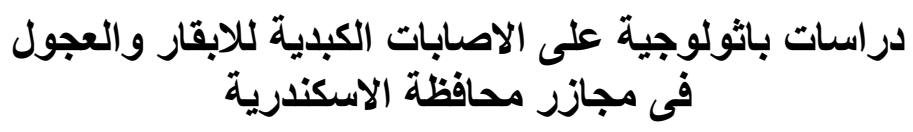

سناء عبدة الشامه ، مريم شهلى بخيت

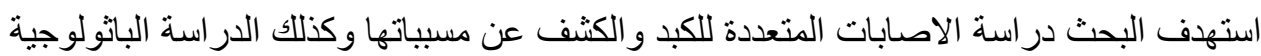

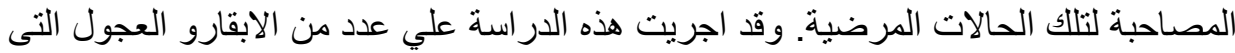

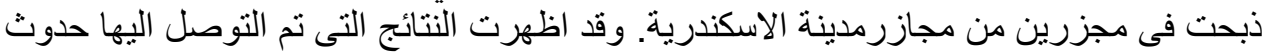

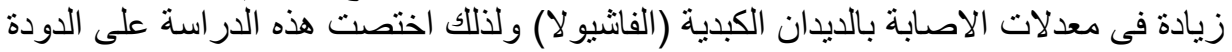

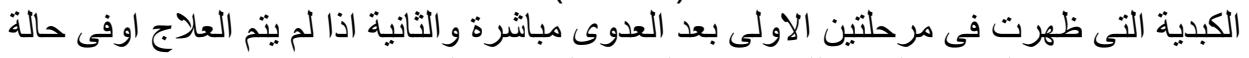

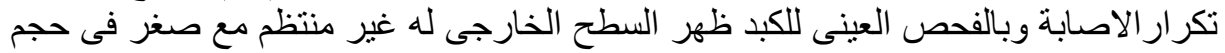

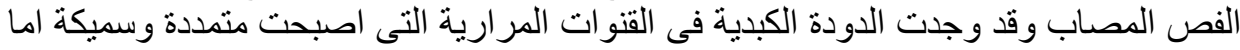

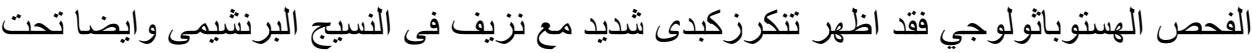

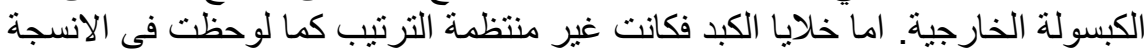

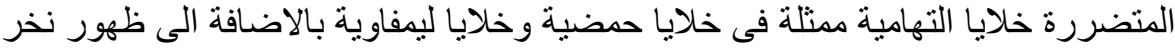

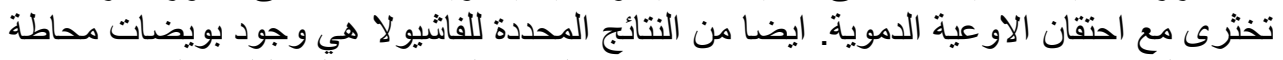

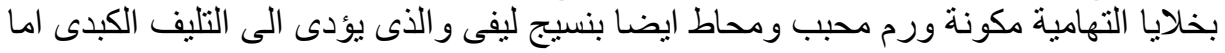

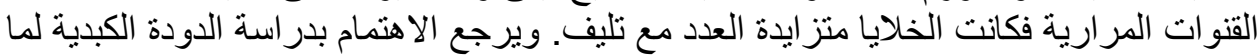

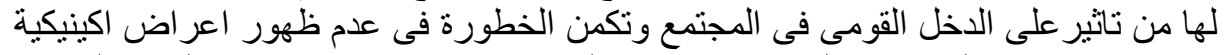

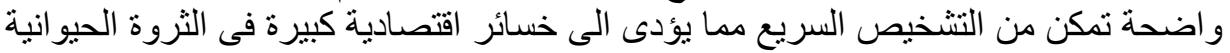
نتيجة فقدان اللحم و اللبن و اصبح الكبد غير صالح للاستهلاك الادمى مع احتمال ان تمند الاصيابة الإنية الى الانسان. 


\section{SUMMARY}

This study aimed to demonstrate the pathological changes of the liver of cow and calves slaughtered in Alexandria governorate caused by fasciola. In the present investigation, the affection rate of the liver by fasciola was high. Post mortem examination of affected liver revealed two stages of infection, early stage directly seen as a result of primary infection and the progressive stage as a result of untreated cases or repeated infection. The gross hepatic lesion revealed shrinkage in size especially in the affected lobe with irregular surface and the fluke could be demonstrated in the bile duct. The histo-pathological examination showed coagulative necrosis and heamorrge in hepatic parenchyma, and the hepatic lobule lost its architecture, progressively increasing cellular infiltration especially eosinophil, lymphocyte and macrophage, the proliferation of bile ductules and fibrosis which occurred in adjacent portal triads and interlobular septa. Economic significance of fasciola is mainly due to direct losses caused by decrease of the weight rate, milking capacity and condemnation of altered livers in slaughter house.

Key words: Pathology, liver affections, fascioliasis, cows, calves.

\section{INTRODUCTION}

Slaughter houses provide an excellent opportunity for detecting diseases of both economic and public health importance. Any observation and information obtained at slaughter house can contribute to the understanding of slaughter animal disease. The pathological examination represents a useful to make a diagnosis within the slaughter line (Antia 1982; Orgueinde, 1980).

The liver is one of vital organs of the body, susceptible to various parasites and disease conditions which affect the total health statuse of the animal. Focal liver disease is also common as a result of the organs acting as the vast absorptive area of the gut with all its resident microorganism and parasite (Kelly, 1993).

Fasciolosis is a world wide zoonotic disease and the incidence is reported to be increasing in certain regions of the world and creating a serious public health concern in areas such as Nile delta regions. Infection by members of genus fasciola, commonly known as liver flukes, may be responsible for morbidity and mortality in most mammals species but are particular importance in sheep and cattle to livestock producers (Loyacano et al., 2002). 
Liver fluke transmission is depending on the presence of its snail intermediate host therefore the distribution of the parasite is limited to geographic areas where the appropriate snail species is present. The incidence of affection of liver in Egypt was very high and chronic inflammation with or without fascioliases was found to be the most prevalent lesion causes great economic losses in livestock's (Ayoub, 1983; Hassieb et al., 1995).

Parasites and diseases damage the liver causing economic losses to ranches due to reduction in milk and meat production, also decrease in host fertility by altering normal metabolism andlor balance of sex hormones (Torgerson and Daxton 1999; Ray M Kaplan, 2001) and make the liver unsuitable for human consumption this leads to great losses to live-stock production and condemnation of great numbers of livers in slaughtered houses.

So, the present study has been performed to identify the pathological condition of liver of cattle by using gross and histopathological studies aiming to aid the diagnosis of hepatic affection and the assessment of the degree of infection.

\section{MATERIALS and METHODS}

70 Livers of slaughtered cows and calves were collected and examined for gross pathological abnormalities from two slaughter houses in Alexandra Governorate and histopathology was done in the Department of Pathology Animal Health Research Laboratory in Alexandria. Liver exhibiting gross alteration were cleaned with normal neutral saline and the gross change were recorded. The lesions containing tissue samples were collected in $10 \%$ neutral buffered formalin for fixation. The fixed tissues were processed routinely for paraffin embedding and sections at 3 micron, thickness were done according to the procedure of (Bancroft et al., 1996) were obtained.

The histological sections were stained with heamatoxyline and eosin. The pathological conditions of liver were diagnosed. Parasites present in the liver were collected and examined in fresh state and then washed with normal saline following with distilled water and then kept in formaldehyde -glacial acid -alcohol (AFA) solution. 


\section{RESULTS}

Gross study was performed during collection of samples from slaughter houses primarily and then during trimming of the samples for histopathology.

In this study $25 \%$ of examined livers were found to be affected with fascioliasis irrespective of seasonal variation and sex, sharp seasonal variation and more adult flukes occurs during the winter seasons.

\section{Post mortem examination:}

The post mortem examination of affected liver revealed two stages of infection:

Early stage, the affected liver showed slightly enlarged with rounded edges and thick capsule. The surface of the affected liver showed whitish or reddish discoloration. The cut surface revealed dark red areas of hemorrhage in addition to the situated necrotic foci. Bile ducts were thicked. The lesions vary from mild to sever.

In advanced stage, pipe stem appearance of the liver could be observed. The affected lobe reduced in size and in some cases the liver have irregular out line pale and firm in consistency. Focal lesions contain flukes with different size. Some fluke died producing a dirty, greasy mass under capsule. On cut sections there was considerable amount of diffuse connective tissue.

The bile duct more prominent dilated with thickening of its wall. In cut section of bile duct liver flukes can be seen. In all dissected cases the gall bladder was distended with greenish black secretion containing a few flukes. In most livers the hepatic lymph node were moderately enlarged. In other organs no pathognomic gross changes could be observed.

\section{Histo-pathological finding:}

In all the examined cases the hepatopathic alterations were constant and diagnostic although, some variation in the degree of severity was noticed. Lesions may vary from mild in case of low infection to severe in heavy or repeated infections. In early disease, the alternative changes include hydropic degenerative changes or coagulative necrosis. The hepatocytes were relatively swollen with increase acidophelia of the cytoplasm and pyknotic or even karyolitic nuclei. Necrosis appears in subcapsular and parenchymal areas. There are cellular reactions with infiltration by eosinophils, macrophage, lymphocytes and hypertrophic kupffer cells (Fig. 1A\&B). 
Variable sized foci of hemorrhage were seen in all the examined liver cases. These hemorrhage were either paranchymal or in the portal triads. The blood extravasations were seen either in place of necrotic and lytic hepatic cells or in between the cords to form hemorrhagic migratory tracks. There were heamosidrine pigments in the necrotic and even hemorrhagic areas (Fig. 1C) were observed.

In three examined cases, in addition to the necrobiotic and necrotic changes were associated with atrophy of cords. In between the cords the sinusoids were dilated with of various shapes. These dilated sinusoids contained polymorphnuclear cells (Fig $1 \mathrm{~d}$ ).

In the bile ducts, the epithelium showed hyperplasia and the wall of bile duct become greatly thicked and infiltrated by eosinophils and mononuclear cells that cause chronic cholangiohepatitis. Most of the duct become fibrotic and sometimes calcified (Fig.2A,B). In advanced cases the most characteristic finding was the presence of egg and immature fluke trapped in the parenchyma, and surrounded by giant cell, eosinophil and mononuclear cell infiltration. The Focal necrosis of the hepatic parenchyma were progressively infiltrated with plasma cell lymphocyte and eosinophil (Fig $2 \mathrm{C}, \& \mathrm{D})$ were detected.

In late cases of fasciola, destruction and losses of the hepatic parenchyma were observed which replaced by regenerated nodules and necrotic debris and surrounded by dense connective tissue. The intrahepatic vascular branches revealed endothial degenerative changes and smooth muscle vaculation. Proliferation of fibroblasts replacing the hemorrhagic tract. In some cases the fibrotic areas produce severe destruction and losses of the hepatic parenchyma that will be replaced by proliferation by connective tissue which cause granuloma like or pseudolobulation (Fig. $3 \mathrm{~A} \& \mathrm{~B})$.

Viable hepatocyte was not observed within this area with loss of lobular architecture. In advanced cases, the necrobiotic changes revealed severe destruction of hepatic parenchyma and proliferation of connective tissue in portal tract (Fig. 3 C), infiltration with lymphocyte, Some of hepatocytes showed presence of eosinophilic homogenous circumscribed intracytoplasmic hyaline droplets (Fig.3D). 

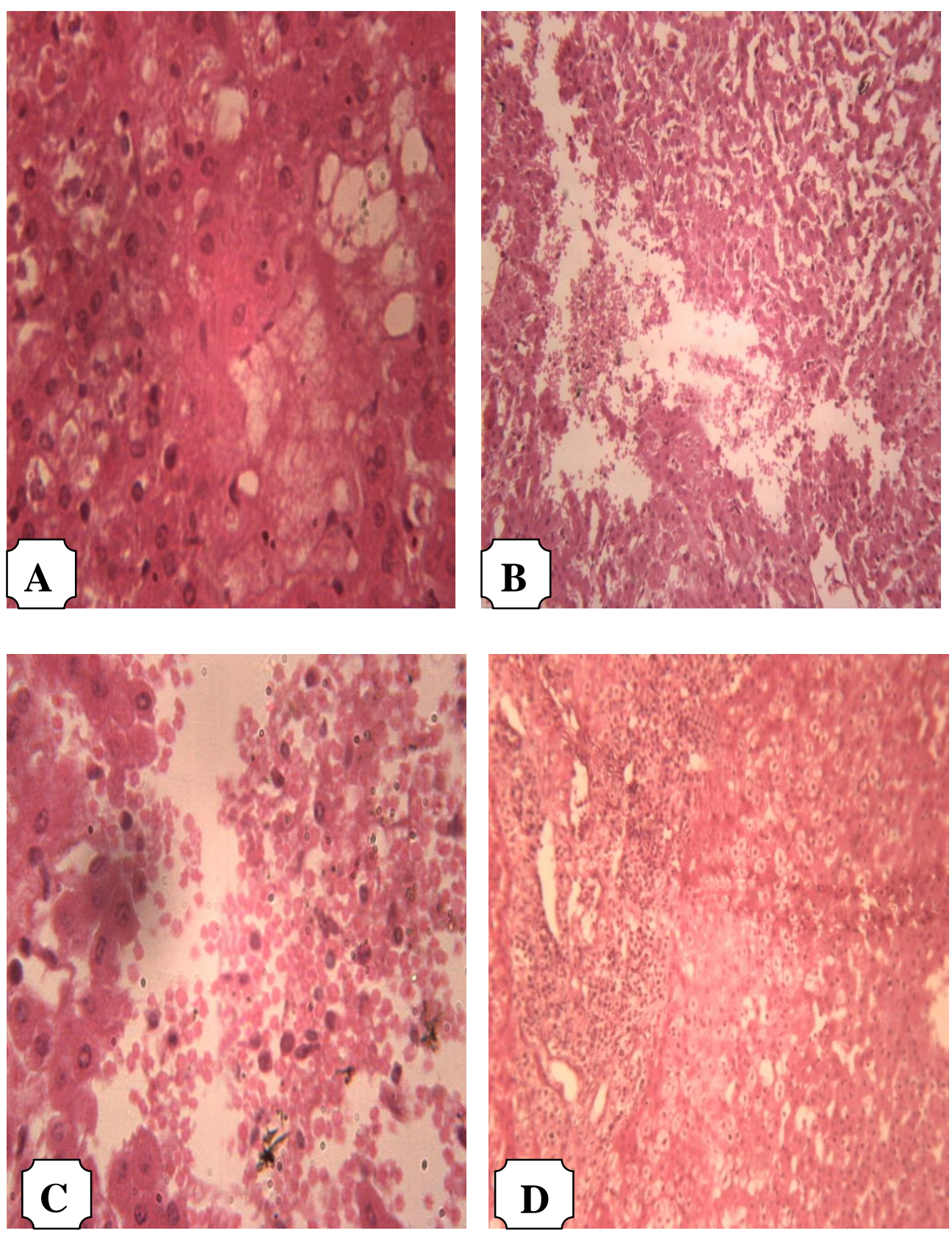

Fig. 1 (A) Early fasciola infected liver showed hydropic degeneration. (B\&C) Large area of necrosis with Hemorrhage. (D) Loss of hepatic cords and dilated sinusoids H\&E. 

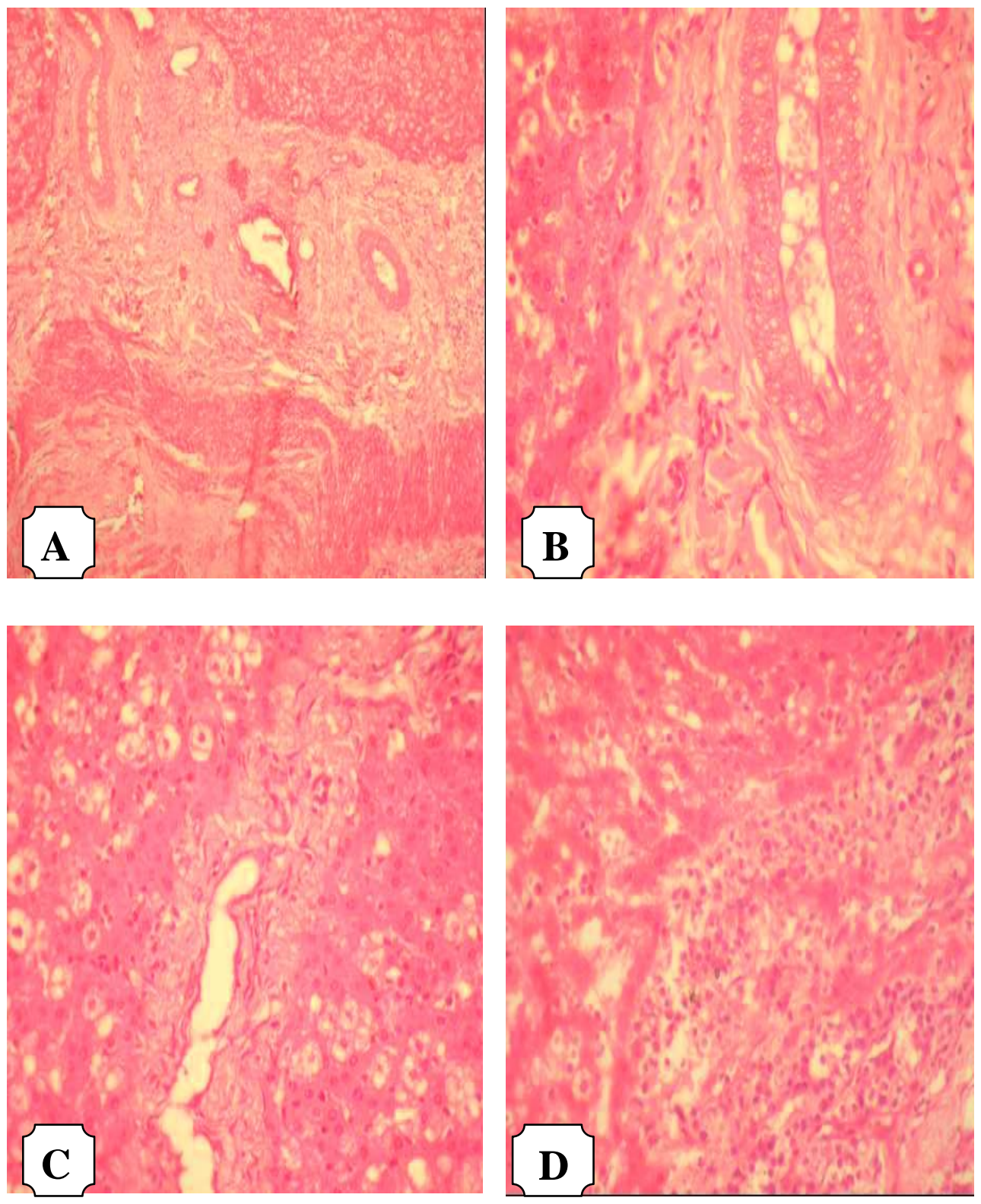

Fig. 2 (A) Advanced infection of fasciola showing chronic cholongitties and fibrosis. (B\&C) Bile duct showed hyperplasia and the wall infiltrated by infiltrative cells. (D) Heavy infiltration of eosinophils and lymphocyte H\&E. 

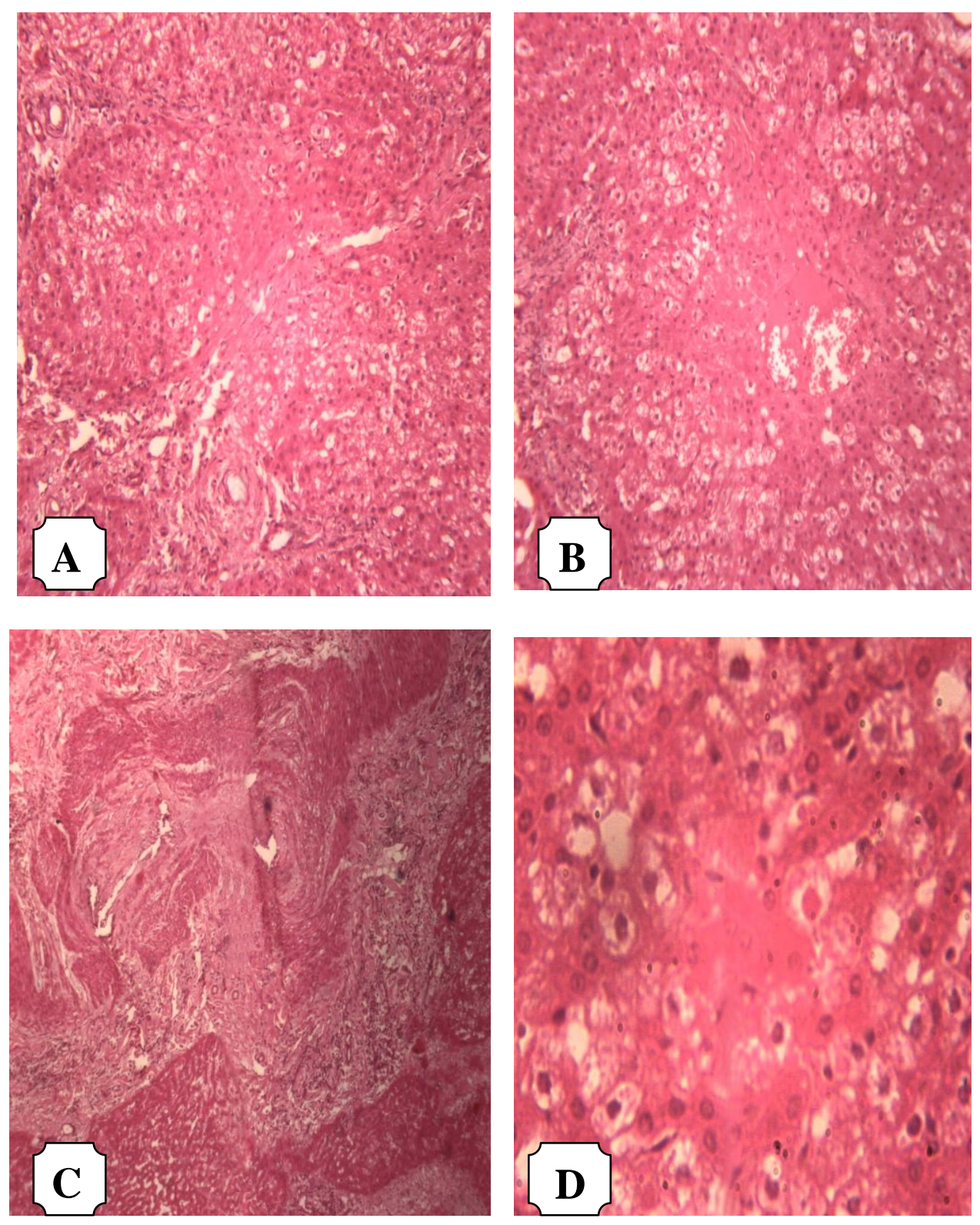

Fig. 3 (A\&B) Liver at late stage of infected fasciola showed pseudolobulation, Necrosis and cellular proliferation and area of haemorrge. (C) Fibrotic portal area. (D) Cytoplasmic easinophilic globule in hepatic cell H\&E. 


\section{DISCUSSION}

In the present investigation concerning the seasonal infection rate of fasciola was during autumn till spring. Mahmoud et al. (2001) found that infection rate was greatly lower than that mentioned by Ammar (1997). This may be due to the progress and development of treatment programs against fasciola in general in recent years. The epidemiology of the disease is also influenced by the grazing habits of animal which grazing in wet marshy areas, favored by the fluke snail are more likely to become infected. Typically long wet seasons are associated with a high rate of infection. Both domestic and wiled animals act as reservoir (Tergerson and Daxton, 1999). Ray (2001) mentioned that clinical disease is caused by extensive damage of the hepatic parenchyma produced by migratory juvenile flukes. Ferre et al. (1994) observed that reduced weight gain of liver flucke infected animals is directly connected to feed efficiency and depression might be related to damaging in the liver parenchyma at the trap of immature liver fluke migration.

The gross examination of fasciola infected liver revealed two stages of fasciola early and advanced. At early stage the affected liver showed slight enlargement with rounded edges and the surface colure was altering between witish and reddish. This result agrees with (Jubb et al., 1996 and Ahmedullal et al., 2007) as they explain the pale brownish areas by migrating the immature flukes through the liver. Molina et al. (2005) mentioned that, in the earlier stage, pale or hemorrhagic migratory tract are present but when the disease advanced the liver becomes generally paler and firmer and the bile ducts become more prominent from dilated to thicked walls. The result obtained by examination the advanced stage are similar which noticed by Mahdi and Al-B. Baldawi, (1987); Makled et al. (1988); Egbi and Chaudria, (1996). Ahmedullah et al. (2007) that pipe stem appearance causes by the migration of parasite. Beham and sangster (1999); Nithisthai et al. (2004), mentioned that fasciola occurs in two phases as paranchymal and biliary, during the paranchymal phase, pathology is caused by damage of tissue during migration include sever liver damage, the biliary stage concedes with fluke residence in the bile duct, biliary obstruction and inflammation but Ray (2001) reported that chronic disease results from a combination of partially resolved hepatic damage that follows the acute phase and the blood sucking activities of the adult flukes within the bile ducts.

The histopathology study showed presence of necrosis and hemorrhage subcapsular and paranchymal this result similar (Molina et al., 2005; Ray 2001), which result in a diffusely fibrotic hepatic parenchyma 
containing hemorrhagic streaks and foci and can predispose cattle to black disease. The study of hepatic changes revealed presence of granulomas like or pseudolobulation surrounding by fibrous connective tissue. This result was similar with that noticed by (Galip et al., 2007). But Nakamura (2004), detected degenerative lesions showed eosinophilic papillary endothelial hyperplasia of interlobular veins and easinophilic membranous structure in the eosinophilic granulometous areas of inflammation.

In the bile duct, the results obtained by Ross (1966) explained that the bile ducts might have been ruptured by the parasite or by stasis so that the eggs passed into parenchyma. Alternatively, fibrotic changes induced by a primary infection might have impeded the migration of the flukes in the second or subsequent infections, to the extent that the migrating parasite mature in the parenchyma before managing to reach their final destination. Ray (2001) consider the lesion in the bile ducts that, the adult flukes produce a mechanical irritation that causes cholangiohepatitis, this lead to dilatation, thickening and extensive fibrosis of the duct wall, resulting in stenosis and calcification.

Spithill et al. (1999); Saba (2005) stated that the disease causes considerable impact in economy of the livestock industry. Economic losses include costs of treatment, labour liver condemnation and losses in production. This along with public health significance of human fasciolyosis.

Strategies used to control fasciola mostly depended on the extend and seasonality of disease transmission. The intermediate hosts ability to survive climatic condition and husbandry practices of cattle forms in their management system (Dalton, 1999). Francisco et al. (2007) reported that the application of the intergraded liver fluke control program and treatment program was supplemented by a training and technical assistance program to educate producers led to a $40 \%$ reduction of the prevalence of fasciola hepatica, 38\% increase in cattle liver weigh and a $75 \%$ increase in milk production over the 2 years of the study.

\section{CONCLUSION}

Fasciola is the common liver fluke which is a worldwide distributed parasitic, flat worm with complex life cycle, it infects cattle and sheep but occasionally also humans after consumption of metacercaria contaminated fruits or herpes (watercress) for example.

In countries such as Egypt, the disease is thought to be hyper endemic. So, to control this problem: 
- Regular use of flukicides forms the basis of current control method In areas where disease is endemic it is necessary to treat sheep threeweakly interval from august to February. Most cattle are housed in winter months and are treated at housing.

- An alternative approach dosing alone to prevent the infection reaching the intermediate host snails.

- Vaccination is one such means of controlling infection. The use of vaccines will prevent drug residues entering the food chain and have no adverse effects on the consumer.

- The development of accurate understanding on the mechanisms of drug action and drug resistance will allows anthelminthic to be deployed in a targeted manner only where a provemnet is demonstrated.

\section{REFERNCES}

Ahmedullah, F.; Akbor, M.; Hadider, M.G.; Hossain, M.M.; Khan, M.A.H.N.; Hossain, M.I. and Shanta, I.S. (2007): Pathological investigation of liver of the slaughtered buffaloes in Barisal district bangl. j.Vet. Med. 5 (1\&2): 81-85.

Ammar, K.M. (1997): Epidemiological studies on nematodes, Trematodes and Cestodes in Ruminants in Kafr El-Sheikh Governorate. $4^{\text {th }}$ Sci. Cong. Egypt. Soc. for Cattle Dis., 7-9 Dec., Assuit, Egypt, page: 81- 88 .

Antia, R.E. (1982): Survey of abattoir data in southern Nigeria. Trop. Animal Health Production 4:2.

Ayoub, A.A.M. (1983): The interpretation of the different testes used for estimation of parasitic status of fasciola gigantica in Gharbia Governorate. Thesis, M.V. Sc. Faculty of Vet. Med. Dept. of Parasitology, Cairo University.

Bancroft, J.D.; Stevens, A. and Turner, D.R. (1996): Theory and practice of histological techniques $4^{\text {th }}$ ed. Churchill Living Stone, New York Edinburgh Madrid, San Francisco, Tokyo.

Beham, C.A. and Sangster, N.C. (1999): Pathology, patho-physiology and clinical aspects: Dalton, J.P. ed., fasciolosis. CAB International Wallingford, Oxon, 185-224.

Dalton, JP. (1999): Fascioliosis Lab International Walling Ford Ox, Oxon. Ox108 DE Uk.

Egbe-Nwiyi, T.N. and Chaudrai, S.U.R. (1996): Observation on prevalence, haematological and pathological changes in cattle, sheep and goat naturally infected with Fasciola gigantica in Arid zone of Borno state, Nigeria Pakistan Vet. J. 16(4): 172-175. 
Farancisco Ranunelli, DVM; Msc, Sergio Gonzalez, and DVM, MG, (2007): Strategic control and prevalence of fasciola hepatica in cagamarca, Peru, A pilot study intern. J. Appl. Res. Vet. Med. $7,4$.

Ferre, I.; Barrio, J.P.; Gomzalez-Chalego, J. and Royo Vazquez, F.A. (1994): Appetite depression in sheep experimentally infected with Fasciola hepatica Vet. Parasitology . 55: 71-9o .

Galip Kaya, Emine Ozlem Atesoglu, and Atila Akca (2007): Fasciola hepatica egg -induced granuloma in a bovine liver: a case report. Medcyna wet .63(2): 175-177.

Hassieb, M.M.; El-Manakhly, E.M. and Khater, O.R. (1995): Incidence and pathology of some hepatic lesion in buffalo Egypt. J. of Comp. Path. and Clin. Path; 8, 1-8.

Jubb, R.V.E.; Kennedy, P.C. and Palmer, N. (1993): Pathology of domestic animals $4^{\text {th }}$ ed Vol.2 Academic press New York, Bosten, London.

Kelly, W.R. (1993): The liver and biliary system, In: pathology of Domestic Animals $4^{\text {th }}$ ed, Jubb KVF, Kennedy, PC and Palmer, N (eds.), Academic Press, London, UK.

Loyacano, A.F.; Williams, J.C.; Gurie, J. and DeRossa, A.A. (2002): Effect of gastrointestinal nematode and liver fluke infection on weigh gain and reproductive performance of beef heifers. Vet. Parasitol, 107 (3): 227-34.

Mahdi, N.K. and Al-Baldawi, F.A. (1987): Hepatic fasciolasis in abattoirs of Basrah. Animal Tropical Medicineand Parasitolgy 81 (4) 377-379.

Mahmoud, A. El-Siefy; Nasr M. El-Bahy and Reda E. Ibrahim (2001): Egypt Soc. For Cattle Dis. $6^{\text {th }}$ Sci. 4-6 Dec. Assiut, Egypt 190-98.

Makled, I.; Kalil, H.M.; Abdalla, H.M. and Elzayyat, E.A. (1988): Fascioloses and hepaticaffection. J. of Egyprian Soc. Parasitology, 18(1): $1-10$.

Molina, E.C.; Skerratt, L.F. and Campbell (2005): Pathology of fasciolosis in large ruminants. Tropical animal health and production: 94-98

Nakamura, N. (2004): Parasitic lesions of bovine liver attributed to Capillaria species. J. of Comparative Pathology, 132, 2-3: 228-231.

Nithisthai, S.; Anantaphruti, M.T.; Waikagul, J. and Galhar, A. (2004): Waterborn zoonotic helminthiases Vet.Parasitol 126: 167-193.

Orguneinde, A. (1980): Economic importance of bovine fascioliasis in Nigeria Trop. Animal Health Prod. 12:2.

Ray, M. Kaplan and DVM, phD (2001): Fasiola hepatica: A Review of the economic impact in cattle and consideration for control. Vet. Therapiotics 2, 1: 40-50. 
Ross, J.G. (1966): An abattoir survey of cattle liver infections with Fasciola hepatica. Vet. J. 122: 489-494.

Saba (2005): Human fasciolasis Clinical Microbiology Newsletter 27: 27- 34.

Spithill, T.W.; Smoker, P.M.; Daxton, J.L.; Bozas, E.; Morrison, C.A.; Greaancy, J. and Darsons, J.C. (1999-b): Development of vaccinance against Fascioola hepatica, In fasciolosis, G .P Dalton ed. Wallingford. UK. (p.p. 377-410).

Torgerson and Daxton (1999): Epidemology and control in fasciolosis. J.P. Dalton.ed. walling ford .UK. (ABI: pp.113-150). 
Assiut Vet. Med..J. Vol. 57 No. 129 April 2011 

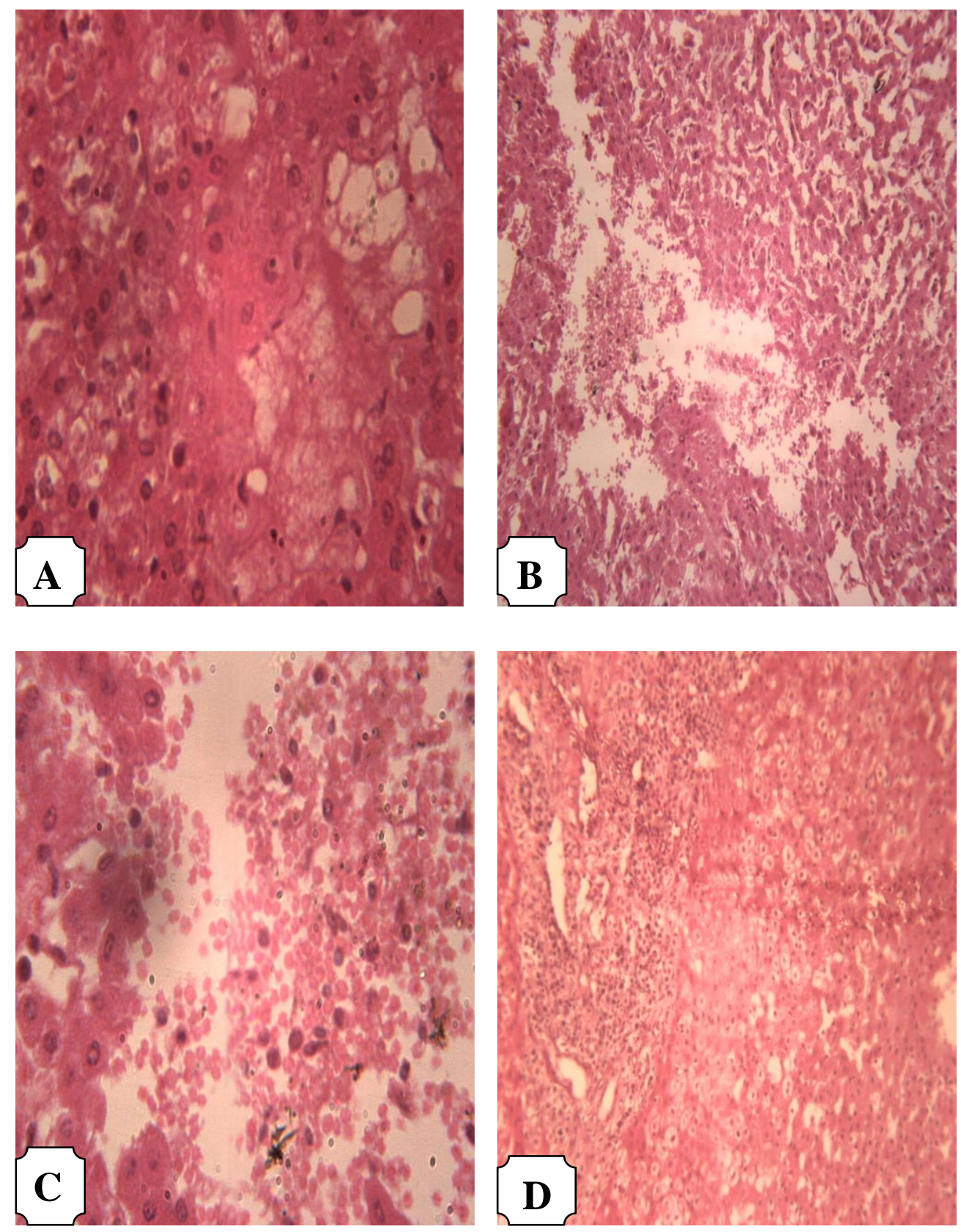

(Fig. 1 A): Early fasciola infected liver showed hydropic degeneration. B\&C) Large area of necrosis with Hemorrhage. D) Loss of hepatic cords and dilated sinusoids $\mathrm{H} \& \mathrm{E}$. 

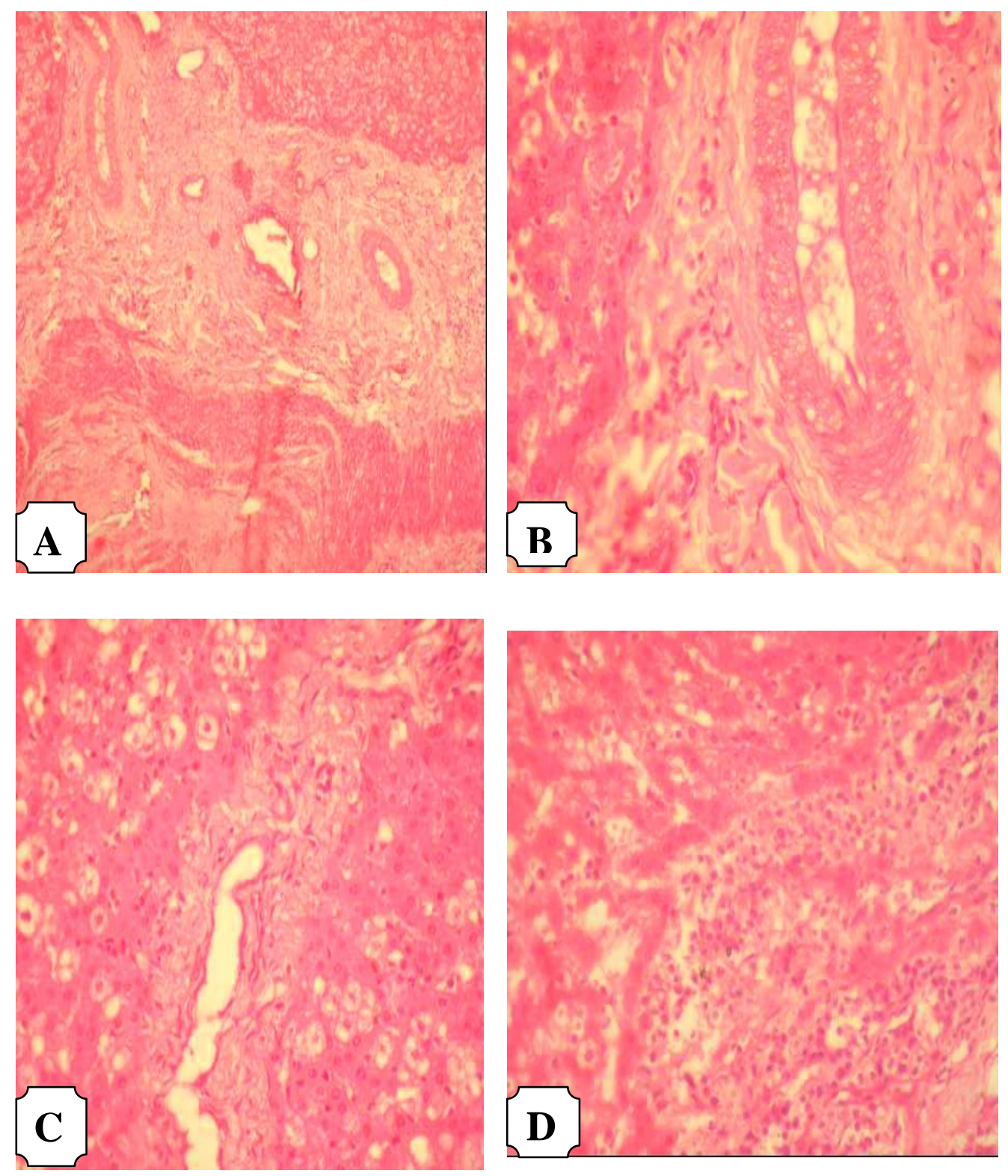

(Fig. 2 A) Advanced infection of fasciola showing chronic cholongitties and fibrosis. B\&C) Bile duct showed hyperplasia and the wall infiltrated by infiltrative cells. D) Heavy infiltration of eosinophils and lymphocyte H\&E. 

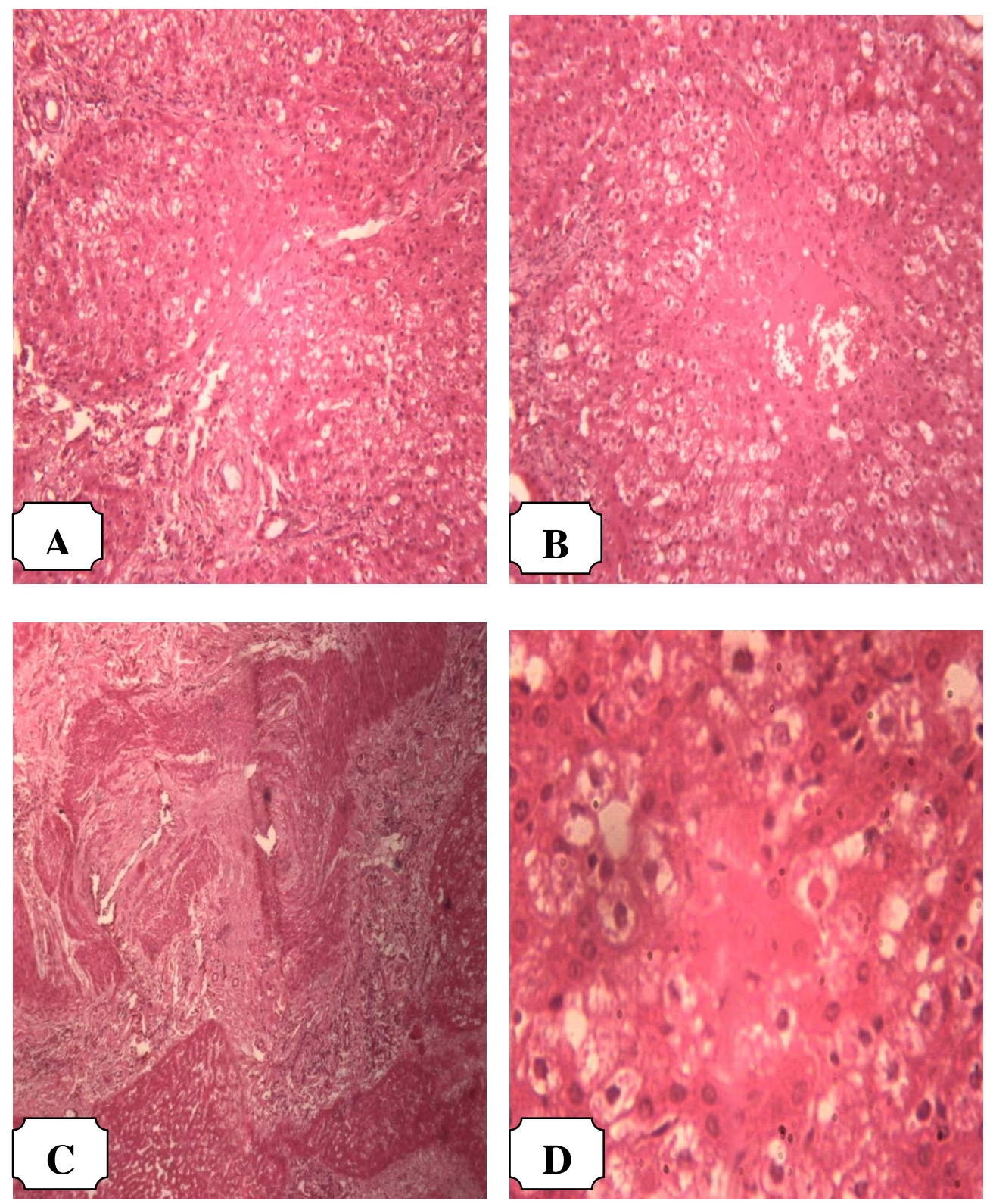

(Fig. 3 A\&B) Liver at late stage of infected fasciola showed pseudolobulation, Necrosis and cellular proliferation and area of haemorrge. C) Fibrotic portal area. D)Cytoplasmic easinophilic globule in hepatic cell $\mathrm{H} \& \mathrm{E}$. 
Assiut Vet. Med..J. Vol. 57 No. 129 April 2011 